Note

\title{
LC-MS Analysis of the Emetic Toxin, Cereulide, Produced by Bacillus cereus
}

\author{
SHIGEKO UEDA ${ }^{1 *}$, HAJIME NAKAJIMA ${ }^{2}$, MIKI IWASE$^{1}$, \\ KUNIHIRO SHINAGAWA ${ }^{3}$, AND YOSHIHIRO KUWABARA ${ }^{1}$ \\ 1 Laboratory of Hygiene, Kagawa Nutrition University, \\ 3-9-1, Chiyoda, Sakado-shi, Saitama 350-0214, Japan \\ ${ }^{2}$ Technology and Research Institute, Meg Snow Brand Milk Products Co. Ltd \\ Minamidai 1-1-2, Kawagoe 350-1165, Japan \\ 3/wate University, 3-18-8, Ueda, Morioka, Iwate 023-8550, Japan
}

Received 11 July, 2012/Accepted 21 August, 2012

\begin{abstract}
A quantitative and chemical assay of cereulide produced in the cultures by some strains of Bacillus cereus was performed on a HPLC and a ESI electrospray ion trap mass analyzer, using the synthetic cereulide as a standard. All 20 strains of emetic $B$. cereus were found to produce $27-740 \mathrm{ng} / \mathrm{ml}$ of cereulide by the LC-MS analysis. In contrast, none of the 10 diarrheal strains produced it. $10^{2} \mathrm{cfu} / \mathrm{ml}$ of the cereulide producible strain with a $210 \mathrm{ng} / \mathrm{ml}$ yield was inoculated into the $10 \%$ suspensions of 14 food products, and was incubated at $32^{\circ} \mathrm{C}$ for $24 \mathrm{~h}$. The $B$. cereus counts in the cultures grew in the order of $10^{8}$ to $10^{\circ} \mathrm{cfu} / \mathrm{ml}$, although the bacteria could not grow in fruits, and the yields of cereulide ranged from $5.18 \mu \mathrm{g}$ in curry to 0.03 $\mu \mathrm{g} / \mathrm{g}$ of raw material and/or powder material, except for fruits. These culture supernatants were also tested for the biological activity in the HEp-2 cell culture assay. Consequently, a certain correlation was shown between the yields of cereulide and the HEp-2 vacuolation activities. In addition, the supernatants were administered i.p. to 5 Suncus marinus test animals. The emetic dose was calculated to be approximately $16 \mu \mathrm{g} / \mathrm{kg}$.
\end{abstract}

Key words : Bacillus cereus / Cereulide / LC-MS / Suncus marinus.

Bacillus cereus is commonly found in nature and is now established as an etiological agent of two distinct types of food poisoning characterized either by diarrhea and abdominal pain 8 to $16 \mathrm{~h}$ after ingestion of the contaminated food (the diarrheal syndrome) or by nausea and vomiting with an incubation period of $<1$ to $5 \mathrm{~h}$ (the emetic syndrome). While the diarrheal syndrome is caused by heat-labile enterotoxins, the emetic syndrome has been found to be caused by a heat-stable toxin named cereulide (Ehling-Schultz et al.,2004; Stenfors et al.,2008). The emetic toxin, cereulide, is a cyclic dodecadepsipeptide (D-O-LeuD-Ala-L-O-Val-L-Val) ${ }_{3}$ (Agata et al., 1994). The toxic effects of cereulide on eukaryotic cells are caused by

*Corresponding author. Tel : +81-49-282-7343 the ionophoric uptake of $\mathrm{K}^{+}$, resulting in dissipation of the transmembrane potential, stimulating swelling and respiration in mitochondria, and finally resulting in their inactivation (Mikkola et al., 1999). The effect of cereulide on mitochondria is used in several assays to detect the toxin in food products, like the HEp-2 cell vacuolation assay (Hughes et al.,1988; Ehling-Schultz et al., 2005) and the sperm motility inhibition assay (Rajkovic et al., 2007). Chemical assays for cereulide quantification using liquid chromatography-mass spectrometry (LC-MS) have been described by Haggblom et al. (2002), Hormazabal et al. (2004), Bauer et al. (2010), and Biesta-Peters et al. (2010). In the present study, the LC-MS analysis was applied to quantitating cereulide produced by various B. cereus strains from samples of foods 
incriminated in food poisoning cases. The relation of the cereulide yield and the biological activity in the HEp-2 cell assay was evaluated for the culture supernatant. In addition, the emetic activity of the supernatant of cereulide producing strains was biologically examined by its intraperitoneal administration to Suncus marinus.

The $B$. cereus strains used in the study were 20 starch non-hydrolyzable strains implicated in emetic syndrome food poisoning cases and 10 starch hydrolyzable strains causing the diarrheal type. Strain 13 was used as the representative emetic agent (Ueda and Kuwabara, 2011) and in tests for cereulide yield after inoculation to some food samples. For analysis of cereulide, the strains were cultivated by shaking vigorously in $10 \%$ skim milk at 32 ${ }^{\circ} \mathrm{C}$ for $24 \mathrm{~h}$, and then the cultures were centrifuged at $8,000 \mathrm{rpm}$ for $5 \mathrm{~min}$ and filtrated through the membrane filter ( $0.45 \mu \mathrm{m}$; Toyo Roshi Kaisha, Ltd.) for collecting the supernatants. The solvent was evaporated under reduced pressure, the residue was dissolved in methanol, and the solution was applied onto the top of an Oasis ${ }^{R}$ HLB extraction cartridge (Nihon Waters K.K.) conditioned with methanol, followed by water. The cartridge was rinsed with water, the target compound was eluted with methanol, and after the effluent was dried under reduced pressure, it was dissolved in 95\% methanol for the LC-MS analysis.

The LC-MS analysis was performed on a Paradigm MS2 HPLC (Michrom Bioresources) and a LTQ Velos ESI electrospray ion trap mass analyzer (Thermo Scientific), and the operating conditions of
LC-MS for analysis of cereulide are shown in Table 1. An external standard used the synthetic cereulide prepared on the basis of the description of Isobe et al. (1995). The purity of the solution was $>98 \%$. The calibration curve of cereulide was linear in the range of concentration of $0,2.5,5.0$ and $7.5 \mathrm{ng} / \mathrm{ml}$. The liquid chromatograms of 2.5 and $5.0 \mathrm{ng} / \mathrm{ml}$ of synthetic cereulide are illustrated in Fig. 1-(1) and (2). Also, the chromatograms of extracts from $B$. cereus strain 13

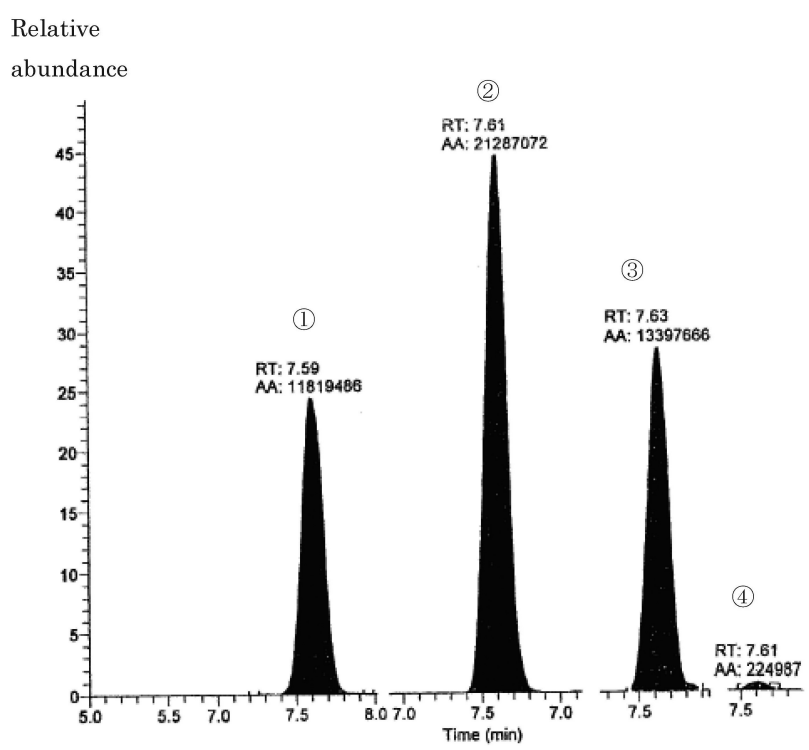

FIG. 1. LC chromatograms of (1) synthetic cereulide:2.5 $\mathrm{ng} / \mathrm{ml}$; (2)synthetic cereulide:5.0 ng/ml; (3)extract of $10 \%$ skim milk inoculated with emetic B.cereus 13 and incubated for $24 \mathrm{~h}$ at $32^{\circ} \mathrm{C}$; (4)blank :extract of $10 \%$ skim milk.

TABLE 1. Operating conditions of LC/MS for analysis of cereulide.

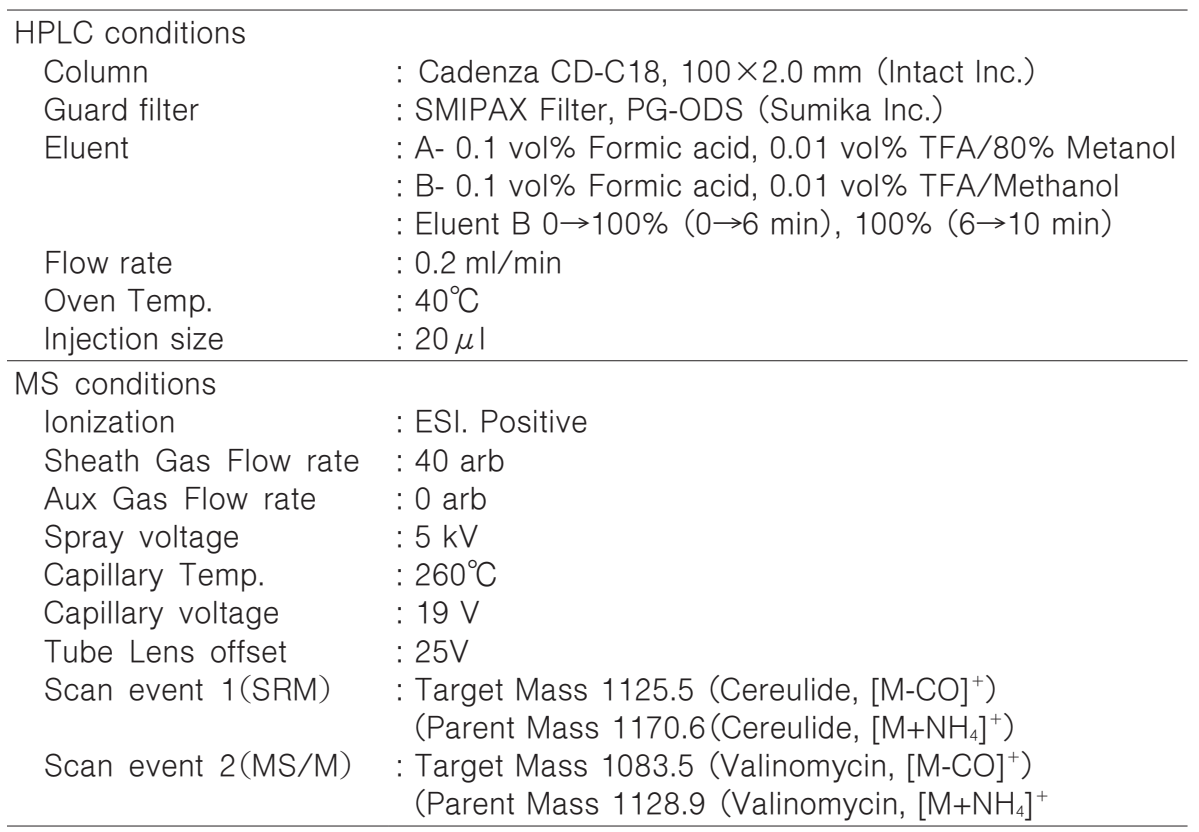


skim-milk culture and $10 \%$ skim milk control are shown similarly in Fig.1-(3) and (4). The detection limit of LC-MS analysis was $0.02 \mathrm{ng} / 10 \mu \mathrm{l}$. The average value for recovery of $5.0 \mathrm{ng}$ cereulide/ml of skim milk was $95.5 \%$ in 3 repeated extraction-analysis experiments. Furthermore, after $10 \%$ suspensions of several food product samples inoculated with $10^{2} \mathrm{cfu} / \mathrm{ml}$ of emetic $B$. cereus strain 13 were incubated with vigorous shaking at $32^{\circ} \mathrm{C}$ for $24 \mathrm{~h}$, the bacterial plate counts were enumerated and their cereulide contents were analyzed by the LC-MS for extracts prepared by the similar procedure as described previously.

The HEp-2 cell vacuolation assays were carried out on the above culture supernatants according to the method of Szabo et al. (1991). A $25 \mu$ I aliquot of twofold serially diluted supernatant samples was placed in each well of a 96-well microtiter plate (Becton Dickinson Labware, Franklin Lakes, NJ). The HEp-2 cell cultures freshly seeded were trypsinized, suspended at about $2 \times 10^{4}$ cells $/ \mathrm{ml}$ in the growth medium with serum, and distributed in aliquots of per well containing the test samples. The titer was recorded as the inverse of the highest dilution showing vacuole formation.

In the chemical assay for quantification using LCMS, a solution with a known concentration of cereulide was needed as a standard in order to determine the content in a sample. Valinomycin which is the cereulide-like ionophore has been used as a standard (Haggblom et al.,2002), since a standard of cereulide is unavailable commercially. In this study, the synthetic cereulide was used as a standard as described above. The results of the producibility of the emetic toxin assayed on 20 strains isolated from the materials of the emetic food poisonings and 10 strains from the diarrheal type were shown in Table 2. All of the emetic strains presented the positive reaction in the immunochromatographic assays which targeted a marker protein co-expressed during the synthesis of cereulide (Ueda and Kuwabara, 2011) and the producibility of the emetic toxin in both the bioassays with the HEp-2 cells and the LC-MS assays. Also, the results of the bioassay and the LC-MS analysis were almost parallel. On the other hand, it was found in all assays that none of the 10 diarrheal strains produced the emetic toxin.

Subsequently, $10^{2} \mathrm{cfu} / \mathrm{ml}$ of $B$. cereus strain 13 with the titer of 320 in the HEp-2 cells assay and the cereulide yield of $210 \mathrm{ng} / \mathrm{ml}$ in the above experiment was inoculated into the $10 \%$ suspensions of 14 food products such as potato salad, soybean flour, hard bean curd and so on, and was incubated at $32^{\circ} \mathrm{C}$ for $24 \mathrm{~h}$. The B. cereus counts in the cultures grew in the order of $10^{8}$ to $10^{9} \mathrm{cfu} / \mathrm{ml}$, although the bacteria could
TABLE 2. Production of cereulide by Bacillus cereus strains isolated from foods involved in food poisoning cases.

\begin{tabular}{|c|c|c|c|c|}
\hline \multirow{3}{*}{ Strain No. } & \multirow{3}{*}{ Serovar } & \multicolumn{3}{|c|}{ Result of IC Emetic toxin production by } \\
\hline & & \multirow{2}{*}{$\begin{array}{l}\text { assay for } \\
\text { emetic toxin }\end{array}$} & \multirow{2}{*}{$\frac{\text { LC-MS/MS }}{: \mathrm{ng} / \mathrm{ml}}$} & \multirow{2}{*}{$\begin{array}{c}{\text { Bioassay }{ }^{2}} \\
\text { : titre }\end{array}$} \\
\hline & & & & \\
\hline \multicolumn{5}{|c|}{ Starch non-hydrolyzable emetic strains } \\
\hline 7 & 1 & + & 220 & 160 \\
\hline 13 & 1 & + & 210 & 320 \\
\hline 14 & 1 & + & 740 & 320 \\
\hline 16 & $\mathrm{UT}^{3)}$ & + & 430 & 10 \\
\hline 17 & UT & + & 600 & $T^{4)}$ \\
\hline 26 & 1 & + & 240 & 80 \\
\hline 27 & 1 & + & 390 & 80 \\
\hline 28 & 1 & + & 27 & 320 \\
\hline 29 & 1 & + & 140 & 80 \\
\hline 31 & 1 & + & 23 & 40 \\
\hline 33 & 1 & + & 210 & 180 \\
\hline 52 & UT & + & 410 & 80 \\
\hline 54 & 1 & + & 69 & 160 \\
\hline 55 & 1 & + & 380 & 320 \\
\hline 58 & 1 & + & 150 & 160 \\
\hline 60 & 1 & + & 41 & 160 \\
\hline 62 & 1 & + & 45 & 160 \\
\hline 63 & 1 & + & 640 & 160 \\
\hline 64 & 1 & + & 49 & 160 \\
\hline 65 & 1 & + & 680 & 160 \\
\hline \multicolumn{5}{|c|}{ Starch hydrolyzable diarrheal strains } \\
\hline 6 & UT & - & $N D^{6)}$ & $\mathrm{Neg}^{5}$ \\
\hline 8 & 1 & - & ND & Neg \\
\hline 18 & UT & - & ND & $\mathrm{Neg}$ \\
\hline 19 & UT & - & ND & Neg \\
\hline 35 & UT & - & ND & Neg \\
\hline 36 & UT & - & $\mathrm{T}$ & Neg \\
\hline 39 & UT & - & ND & Neg \\
\hline 46 & UT & - & ND & Neg \\
\hline 49 & UT & - & $\mathrm{T}$ & Neg \\
\hline 51 & UT & - & $\mathrm{T}$ & Neg \\
\hline
\end{tabular}

1) examined by immunochromatographic assay (Ueda et al., 2011)

2) assayed with Hep-2 cells.

3) unidentified

4) trace

5) negative reaction

6) not detected

not grow in juice samples such as orange and kiwifruit (Table 3 ). The supernatants were assayed for the emetic toxin activities by the HEp-2 cell assay and the LC-MS analysis as described above. As shown in Table 3, the yields of cereulide ranged from $5.18 \mu \mathrm{g}$ in curry to $0.03 \mu \mathrm{g} / \mathrm{g}$ of raw material and/or powder material, except fruits. The activities of the HEp-2 cell vacuolation were observed in the culture supernatants of food materials except for orange and kiwifruit. The samples which yielded cereulide of more 
than $1.0 \mu \mathrm{g} / \mathrm{g}$ showed the titers of more than 80 -fold in the HEp-2 cell assays, and those yielding 0.03 $0.06 \mu \mathrm{g} / \mathrm{g}$ of cereulide were the titers of less than 10fold. Thus, a certain correlation was shown between the yields of cereulide and the HEp-2 vacuolation activities.

Biesta-Peters et al. (2010) described that the use of valinomycin as a standard results in quantification of cereulide in terms of valinomycin equivalents, which is an elegant method but also scientifically debatable, since the compounds are different and might therefore show different behaviors in biological and chemical assays. Haggblom et al. (2002) found that MS results for valinomycin and cereulide were within 10\%. However, Biesta-Peters et al. (2010) reported that quantification of cereulide in samples by using valinomycin as the standard overestimated the concentration compared to that obtained using synthetic cereulide as the standard, and using valinomycin, the levels were approximately 10\% higher. Therefore, commercially available cereulide is needed for the detection and quantification of cereulide in food samples.

Suncus murinus (house musk shrew) is a small laboratory animal belonging to order Soricomopha, and shows an emetic response to certain physical and chemical stimulants unlike mice and rats (Andrews et al., 1996). Agata et al. (1995) tested the emetic effects of synthetic and natural cereulide in Suncus murinus. In this study, the effect of emetic $B$. cereus strain 13 culture was tested on Suncus murinus. In the result by the above LC-MS analysis, the cereulide content in the culture-supernatant was $210 \mathrm{ng} / \mathrm{ml}$. One, 2, 4 and $5 \mathrm{ml}$ aliquots of the supernatant were administered intraperitoneally to 5 test animals per each group, and the dose of cereulide was estimated to be 3.5, 6.0, 12.0 and $16.2 \mu \mathrm{g} / \mathrm{kg}$, respectively. All animals of the group given $5 \mathrm{ml} \mathrm{vom-}$

TABLE 3. Cereulide production and denaturation activity of Hep-2 cells after 24 h-incubation of food samples ${ }^{1)}$ inoculated with $10^{2} \mathrm{cfu} / \mathrm{ml}$ of B.cereus strain 13 .

\begin{tabular}{lccc}
\hline Food sample & $\begin{array}{c}\text { Yield of cereulide } \\
\text { produced in sample }{ }^{2)} \\
(\mu \mathrm{g} / \mathrm{g})\end{array}$ & $\begin{array}{c}\text { Titres by } \\
\text { Hep-2 } \\
\text { bioassay }\end{array}$ & $\begin{array}{c}\text { B.cereus counts after } \\
24 \mathrm{~h} \text { incubation } \\
(\text { log of cfu/ml) }\end{array}$ \\
\hline Potato salad & 3.73 & 1,280 & 9.2 \\
Soy bean flour & 1.84 & 160 & 8.9 \\
Hard bean curd (Koritoufu) & 1.74 & 600 & 9.1 \\
Bean curd (Toufu) & 2.73 & 320 & 8.9 \\
Vegetable cream soup & 1.58 & 80 & 8.5 \\
Wheat flour : medium & 0.65 & 40 & 8.6 \\
Curry & 5.18 & 160 & 8.9 \\
Savory steamed egg custard (Chawanmushi) & 2.62 & 160 & 9.1 \\
Chicken consomme soup & 0.27 & 20 & 9.1 \\
Macaroni powder & 0.06 & 10 & 8.8 \\
Boiled rice & 0.03 & 10 & 8.6 \\
Compound boiled rice (Gomokumeshi) & 0.03 & 5 & 9.3 \\
Orange & 0 & - & $<2.0$ \\
Kiwifruit & 0 & - & $<2.0$ \\
\hline
\end{tabular}

1) Food samples were used as $10 \%$ suspension and incubated at $32^{\circ} \mathrm{C}$.

2) The result was expressed as yield per solid material.

TABLE 4. Emetic effects of emetic B.cereus strain 13 culture-supernatant on Suncus murinus ${ }^{1)}$ after intraperitoneal administration.

\begin{tabular}{|c|c|c|c|c|c|c|}
\hline \multirow[b]{2}{*}{ Group } & \multicolumn{2}{|c|}{ Supernatant administered } & \multirow[b]{2}{*}{$\begin{array}{c}\text { Dose } \\
(\mu \mathrm{g} / \mathrm{kg})\end{array}$} & \multirow{2}{*}{$\begin{array}{c}\text { No. of } \\
\text { animals } \\
\text { vomiting }\end{array}$} & \multirow[b]{2}{*}{$\begin{array}{l}\text { Latency } \\
\text { (min) }\end{array}$} & \multirow[b]{2}{*}{$\begin{array}{l}\text { Other primary } \\
\text { symptoms }\end{array}$} \\
\hline & $(\mathrm{ml})$ & $\begin{array}{l}\text { cereulide }^{2)} \\
(\mathrm{ng} / \mathrm{ml})\end{array}$ & & & & \\
\hline I & 1 & 210 & 3.5 & $0 / 3$ & & abdominal cramp \\
\hline II & 2 & 420 & 6.0 & $0 / 3$ & & abdominal cramp \\
\hline III & 4 & 840 & 12.0 & $0 / 3$ & & abdominal cramp \\
\hline IV & 5 & 1050 & 16.2 & $3 / 3$ & $5.5 \pm 1.0$ & abdominal cramp \\
\hline control $^{3)}$ & 5 & - & - & $0 / 3$ & & normal \\
\hline
\end{tabular}

1) Average body weight of each group was $65 \pm 3 \mathrm{~g}$.

2) Cereulide contents were estimated on the basis of LC/MS analysis.

3) Administration of medium alone. 


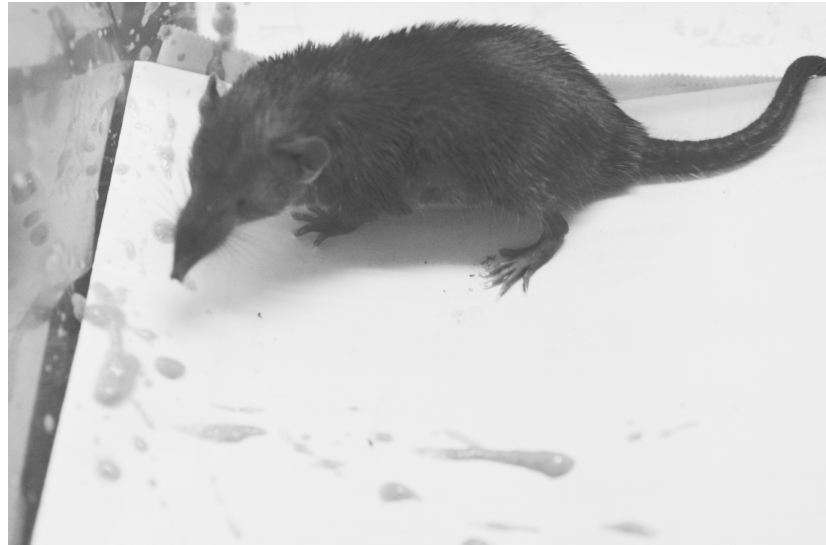

FIG. 2. Vomiting Suncus murinus 5 min after administration of $5 \mathrm{ml}$ of B. cereus 13 culture supernatant (crude cereulide) i.p.

ited 5 to 6 min after administration while vomiting was not observed in other groups as shown in Table 4. Vomiting episodes in the $5 \mathrm{ml}$-group were seen several times during the observation period (Fig.2). Thus, the emetic dose was approximately $16 \mu \mathrm{g} / \mathrm{kg}$. This dosage was identical almost with the results of Isobe et al. (1995).

\section{REFERENCES}

Agata, N., Mori, M., Ohta, M., Suwan, S., Ohtani, I., and Isobe, M. (1994) A novel dodecadepsipeptide, cereulide, isolated from Bacillus cereus causes vacuole formation in Hep-2 cells. FEMS Micrbiol. Lett., 121 31-34.

Agata, N., Ohta, M., Mori, M., and Isobe, M. (1995) A novel dodecadepsipeptide, cereulide, is an emetic toxin of Bacillus cereus. FEMS Microbiol. Lett., 129, 17-20.

Andrews, P., Torii, P., Saito, H., and Matsuki, N. (1996) The pharmacology of the emetic response to upper gastrointestinal tract stimulation in Suncus murinus. Eur. J. Pharmacol., 307, 305-313.

Bauer, T., Stark, T., Hofmann, T., and Ehling-Schulz, M. (2010) Development of a stable isotope dilution analysis for the quantification of the Bacillus cereus toxin cereulide in foods, J. Agric. Food Chem., 58, 1420-1428.

Biesta-Peters, E.G., Reij, M.W., Blaauw, R.H., in't Veld, P.H.,
Rajkovic, A., Ehling-Schulz, M., and Abee, T. (2010) Quantification of the emetic toxin cereulide in food products by liquid chromatography-mass spectrometry using synthetic cereulide as a standard, Appl. Environ. Microbiol., 76, 7466-7472.

Ehling-Schultz, M., Fricker, M., and Scherer, S. (2004) Bacillus cereus, the causative agent of an emetic type of food-borne illness. Mol. Nutr. Food Res., 48, 479-487.

Ehling-Schultz, M., Vukov, N., Schultz, n., Shaheen, R., Andersson, M., Martbauer, A., and Scheer, S (2005) Identification and partial characterization of the nonribosomal peptide synthetase gene responsible for cereulide production in emetic B.cereus. Appl. Environ. Microbiol., 71, 105-113.

Haggblom, M.M., Apetroaie, C., Andersson, M.A., and Salkinoja-Salonen, M.S. (2002) Quantitative analysis of cereulide, the emetic toxin of Bacillus cereus, produced under various conditions, Appl. Environ. Microbiol., 68, 2479-2483.

Hormazabal, V., O'Sullivan, K., and Granum, P.E. (2004) Quantification of Bacillus cereus emetic toxin (cereulide) in figs using LC/MS. J. Liq. Chromatogr. Rel. Technol., 27, 2531-2538.

Hughes, S., Bartholomew, B., Hardy, J.C., and Kramer, J.M. (1988) Potential application of a Hep-2 cell assay in the investigation of Bacillus cereus emetic-syndrome food poisoning, FEMS Microbiol. Lett., 52, 7-12.

Isobe, M., Ishikawa, T., Suwan, S., Agata, N., and Ohta, M. (1995) Synthesis and activity of cereulide, a cyclic dodecadepsipeptide ionophore as emetic toxin from Bacillus cereus. Bioorg. Med. Chem. Lett., 5, 2855-2858.

Mikkola, R., Saris, N.E., Grigoriev, P.A., Andersson, M.A., and Salkinoja-Salonen, M.S. (1999) Ionophoretic properties and mitochondrial effects of cereulide: the emetic toxin of B.cereus. Eur. J. Biochem., 263, 112-117.

Rajkovic, A., Uyttendaele, A., and Debevere, J. (2007) Computer aided boar semen motility analysis for cereulide detection in different food matrices. Int. J. Food Microbiol., 114, 92-99.

Stenfors-Arnesen, L.P., Fagerlund, A., and Granum, P.E. (2008) From soil to gut: Bacillus cereus and its food poisoning toxins. FEMS Microbiol. Rev., 32, 579-606.

Szabo, R.A., Spiers, J.L., and Akhtar, M. (1991) Cell culture detection and conditions for production of a Bacillus cereus heat-stable toxin. J. Food Protect., 54, 272-276.

Ueda, S., and Kuwabara, Y. (2011) Rapid identification of emetic Bacillus cereus by immunochromatography. Biocontrol Sci., 16, 41-45. 